\title{
Regimen Used to Treat or Prevent Graft Rejection
}

National Cancer Institute

\section{Source}

National Cancer Institute. Regimen Used to Treat or Prevent Graft Rejection. NCI

Thesaurus. Code C159657.

Any regimen that can be used to treat or prevent graft rejection. 